\title{
Maternal and fetal outcome in liver disorders in pregnancy
}

\author{
Ruksana Farooq ${ }^{1 *}$, Mehbooba Beigh², Rahat Abas ${ }^{1}$, Yusra Amin ${ }^{3}$
}

\author{
${ }^{1}$ Department of Obstetrics and Gynaecology, SKIMS, Soura, Srinagar, Jammu and Kashmir, India \\ ${ }^{2}$ Department of Obstetrics and Gynecology, SKIMS Medical College, Bemina, Srinagar, Jammu and Kashmir, India \\ ${ }^{3}$ Department of Physiology, GMC, Jammu and Kashmir, India
}

Received: 09 July 2021

Revised: 15 August 2021

Accepted: 16 August 2021

\section{*Correspondence:}

Dr. Ruksana Farooq,

Email: drruksanafarooq@gmail.com

Copyright: $\odot$ the author(s), publisher and licensee Medip Academy. This is an open-access article distributed under the terms of the Creative Commons Attribution Non-Commercial License, which permits unrestricted non-commercial use, distribution, and reproduction in any medium, provided the original work is properly cited.

\section{ABSTRACT}

Background: Liver disorders comprise 3\% of all pregnancy complications. All liver disorders, pregnancy specific, pregnancy related and pregnancy unrelated disorders have both maternal and fetal effects. The aim of the study was to determine the effect of liver disorders in pregnancy. The objective of this study was to determine the effect of liver disorders on pregnancy outcome.

Methods: All pregnant patients with clinical and biochemical evidence of liver dysfunction were taken as cases. Pregnant women with normal liver function tests were taken as controls. All patients were followed during pregnancy and postpartum. Maternal and fetal outcome was studied.

Results: A total of 140 patients were included- 70 cases and 70 controls. Maternal and fetal outcome was studied in both the groups. PPH and oligohydroamnios were most frequent among cases with $\mathrm{p}$ value of 0.034 and 0.035 respectively. Similarly, pre-term birth, RDS and perinatal asphyxia was more common in cases with a p value of 0.011 , 0.001 and 0.005 respectively.

Conclusions: Study concludes that liver disorders in pregnancy have adverse maternal and fetal complications.

Keywords: RDS, PPH, Liver disorders

\section{INTRODUCTION}

During pregnancy, a number of physiological adaptive changes occur in various organs including liver. High levels of serum estrogen and progesterone affect the metabolic, synthetic and excretory functions of the liver during pregnancy. A battery of tests is required to assess the liver function. Liver disorders comprise upto $3 \%$ of all pregnancy complications. ${ }^{1}$ Liver diseases complicating pregnancy can be pregnancy-specific, pregnancy-related and pregnancy unrelated. The hemodynamic, hormonal and immunological changes not only alter the course of both acute and chronic liver diseases in pregnancy, they also affect the outcome of pregnancy.

The aim of the study was to determine the maternal and fetal outcome in pregnant women with liver disorders.

\section{METHODS}

The study was conducted in the department of obstetrics and gynecology, SKIMS, MCH, Bemina, Srinagar from 2017 to 2019. It was a prospective cohort study. It included 70 cases in study group and 70 cases in control groups. The study group consisted of all pregnant women with features of liver dysfunction (jaundice, pruritus or deranged liver function tests or positive viral serology). It also included pregnant women with chronic liver disorders, hyperemesis gravidarum and preeclampsia. The control group consisted of normal pregnant women with normal liver function tests. The study cases were followed till post-partum period. Detailed history and examination was done. After obtaining the demographic, menstrual and obstetric details, the specific symptoms related to liver dysfunction such as pruritus, nausea/vomiting, epigastric pain, 
jaundice and altered sensorium were asked. Specific history of blood transfusion and drug abuse was enquired. A thorough general and obstetric examination was carried out in all. A complete blood count, liver and kidney function tests, coagulation profile, hepatitis serology, serum bile acids, complete urine examination and ultrasound of hepatobilliary system was performed. Maternal and fetal morbidity and mortality was observed properly. Perinatal and neonatal morbidity and mortality was properly studied after following mothers till end of 6 weeks post-delivery.

\section{Statistical analysis}

The recorded data was compiled and entered in a spread sheet. Continuous variables were expressed as mean \pm SD and categorical variables were summarised as frequencies and percentages. Graphically the data was presented by bar and pie diagrams. Chi square test or Fisher's exact test, whichever appropriate was applied for comparing variables. A p value of less than 0.05 was considered statistically significant.

\section{RESULTS}

Results based on maternal complication, fetal complication and clinical features at presentation among study patients have been mentioned.

Among the study cases, pregnancy specific liver diseases were seen in 57 patients $(81.4 \%)$, pregnancy unrelated liver disorders in 9 patients $(12.9 \%)$ and pregnancy related liver disorders in 4 patients $(5.7 \%)$. The various maternal complications in study cases were oligohydroamnios in 19 patients $(27.1 \%)$, post-partum haemorrhage in 12 patients $(17.1 \%)$, abruption placenta in 5 patients $(7.1 \%)$, antepartum haemorrhage in 3 patients $(4.3 \%)$, shock in 3 patients $(4.3 \%)$, polyhydroamnios in 3 patients $(4.3 \%)$, renal failure in 2 patients $(2.9 \%)$, sepsis in 2 patients $(2.9 \%)$, disseminated intravascular coagulation in 1 patient (1.4\%) and maternal mortality in 1 patient (1.4\%). In control group, oligohydroamnios was found in 9 patients $(12.9 \%)$, postpartum haemorrhage in 4 patients $(5.7 \%)$, abruption placenta in 2 patients $(2.9 \%)$, antepartum haemorrhage in 1 patient $(1.4 \%)$, sepsis in 1 patient $(1.4 \%)$. DIC, shock, renal failure and maternal mortality was not observed in any of the study controls. There was significant statistical difference between two study groups with respect to oligohydroamnios and postpartum haemorrhage, with a p value of 0.035 and 0.034 respectively. In study cases, fetal complications like respiratory distress syndrome was observed in 27 patients $(38.6 \%)$, perinatal asphyxia in 23 patients $(32.9 \%)$, preterm birth in 20 patients $(28.6 \%)$, IUGR in 6 patients (8.6\%), neonatal death in 5 patients $(7.1 \%)$, IUD in 4 patients $(5.7 \%)$, hypoglycaemia in 4 patients $(5.7 \%)$ and neonatal jaundice in 4 patients $(5.7 \%)$. In study controls, respiratory distress syndrome was seen in 10 patients $(14.3 \%)$, perinatal asphyxia in 9 patients $(12.9 \%)$, pre-term birth in 8 patients $(11.4 \%)$, IUGR in 2 patients $(2.9 \%)$, IUD in 1 patient $(1.4 \%)$, hypoglycaemia in 1 patient $(1.4 \%)$ and neonatal jaundice in 1 patient $(1.4 \%)$. There was significant statistical difference between two groups with respect to fetal complications like respiratory distress syndrome, perinatal asphyxia and preterm birth with a $\mathrm{p}$ value of $0.001,0.005$ and 0.011 respectively.

Table 1: Comparison of maternal complications in cases and controls.

\begin{tabular}{|c|c|c|c|c|c|}
\hline \multirow{2}{*}{ Parameters } & \multicolumn{2}{|c|}{ Cases } & \multicolumn{2}{|c|}{ Controls } & \multirow{2}{*}{ P value } \\
\hline & $\mathbf{N}$ & $\%$ & $\mathbf{N}$ & $\%$ & \\
\hline APH & 3 & 4.3 & 1 & 1.4 & 0.619 \\
\hline PPH & 12 & 17.1 & 4 & 5.7 & $0.034 *$ \\
\hline DIC & 1 & 1.4 & 0 & 0.0 & 1.000 \\
\hline Oligohydromnios & 19 & 27.1 & 9 & 12.9 & $0.035 *$ \\
\hline Polyhydromnios & 3 & 4.3 & 1 & 1.4 & 0.619 \\
\hline Abruptio placenta & 5 & 7.1 & 2 & 2.9 & 0.441 \\
\hline Renal failure & 2 & 2.9 & 0 & 0.0 & 0.496 \\
\hline Sepsis & 2 & 2.9 & 1 & 1.4 & 1.000 \\
\hline Shock & 3 & 4.3 & 0 & 0.0 & 0.245 \\
\hline Maternal mortality & 1 & 1.4 & 0 & 0.0 & 1.000 \\
\hline
\end{tabular}

Table 2: Comparison of fetal complications in cases and controls.

\begin{tabular}{|llllll|}
\hline Fetal complications & Cases & \multicolumn{2}{c|}{ Controls } & P & Palue \\
\hline IUD & $\mathbf{N}$ & $\mathbf{\%}$ & 1 & 1.4 & 0.366 \\
\hline IUGR & 4 & 5.7 & 2.6 & 2.9 & 0.275 \\
\hline Pre-term birth & 6 & 28.6 & 8 & 11.4 & $0.011^{*}$ \\
\hline RDS & 20 & 38.6 & 10 & 14.3 & $0.001^{*}$ \\
\hline Perinatal asphyxia & 27 & 32.9 & 9 & 12.9 & $0.005^{*}$ \\
\hline Hypoglycemia & 23 & 5.7 & 1 & 1.4 & 0.366 \\
\hline
\end{tabular}

Continued. 


\begin{tabular}{|c|c|c|c|c|c|}
\hline \multirow{2}{*}{ Fetal complications } & \multicolumn{2}{|c|}{ Cases } & \multicolumn{2}{|c|}{ Controls } & \multirow{2}{*}{$P$ value } \\
\hline & $\mathbf{N}$ & $\%$ & $\mathbf{N}$ & $\%$ & \\
\hline Neonatal jaundice & 4 & 5.7 & 1 & 1.4 & 0.366 \\
\hline Neonatal death & 5 & 7.1 & 0 & 0.0 & 0.058 \\
\hline
\end{tabular}

Table 3: Clinical features at presentation in study cases.

\begin{tabular}{|lll|}
\hline Clinical features & Frequency & Percentage $(\%)$ \\
\hline Nausea/vomiting & 19 & 27.1 \\
\hline Pruritus & 39 & 55.7 \\
\hline Jaundice & 8 & 11.4 \\
\hline Encephalopathy & 4 & 5.7 \\
\hline
\end{tabular}

\section{DISCUSSION}

The present study was conducted to study maternal and fetal outcome in liver disorders in pregnancy. It was a prospective, hospital based observational study. The maximum number of patients in our study was in the age group of 30-34 years and 20-24 years with a mean age of $28.1 \pm 5.37$ years. The above results were consistent with Alokananda et al, mean age in their study was 24.7 years. $^{2}$ Similarly Padmaja et al found mean age to be 28.7 years. ${ }^{3}$ Mean gestational age in our study cases was $32.9 \pm 6.3$ weeks while as in controls it was $34.5 \pm 3.35$ weeks. Similarly, Mishra et al in her study found maximum number of patients at the onset of symptoms after 28 weeks, about $87.5 \%$ of patients in third trimester. ${ }^{4}$ In our study, pruritus was most common clinical feature found in 39 patients $(55.7 \%)$, nausea/vomiting in 19 patients (27.1\%), jaundice in 8 patients (11.4\%) and encephalopathy in 4 patients $(5.7 \%)$. Similarly, Reily et al found pruritus most common complaint in their study. ${ }^{5}$ In our study, oligohydroamnios was found in $27.1 \%$ of cases. Out of these patients, $95 \%$ had favourable outcome owing to proper fetal surveillance. So, far oligohydroamnios had not been studied in any of the clinical studies. PPH was seen in 12 patients $(17.1 \%){ }^{4}$ Among these required blood transfusions with routine administration of vitamin $\mathrm{K}$ to patients of ICP.

Rashid et al found PPH in $20 \%$ of patients. ${ }^{6}$ Similarly, Alokananda et al found incidence of PPH to be $25 \%$. $^{2}$ Abruptio placenta was found in 5 patients (7.1\%). Romero et al found abruptio placenta in $6.6 \%$ of cases, that was consistent with our study. ${ }^{7}$ Out of our 70 cases, one case reported to be was acute fatty liver of pregnancy. The patient was primigravida at 36 weeks of gestation with ultrasound documented IUD with abruption. Patient presented with end organ failure, DIC, shock, ICU admission, coagulopathy and ventilator support. Patient received 10 units of blood and 14 FFPs, but at the end she succumbed. Maternal death was seen in 1 clinical case $(1.4 \%)$ in our study.

Dsouza et al reported maternal death in $2 \%$ of cases that was consistent with our findings. ${ }^{8}$ Respiratory distress syndrome was found in $38.6 \%$ of study cases in our study. Dsouza et al found RDS in $13 \%$ of cases. ${ }^{8}$ Pre-term birth was seen in $28.6 \%$ of study cases. Tiwari et al observed pre-term births in $32.9 \%$ of cases, which was consistent with our results. ${ }^{9}$ Perinatal asphyxia was seen in $32.9 \%$ of study cases in our study. In a study conducted by Patra et al, perinatal asphyxia was observed in $28 \%$ of cases, that was consistent with our findings. ${ }^{10}$ Similarly IUD was seen in $5.7 \%$ of study cases that was consistent with observations of Sumangali et al where IUD was seen in $3 \%$ of cases. ${ }^{11}$ In our study IUGR was seen in $8.6 \%$ of study cases. This was inconsistent with findings of Sumangali et al, where IUGR was seen in $22 \%$ of cases. Neontal hypoglycaemia was seen in $5.7 \%$ of our study cases. ${ }^{11}$

\section{CONCLUSION}

Pregnancy specific liver disorders re fairly common, out of which ICP is common. Pruritus is common symptom. Maternal morbidity was increased in the form of APH, PPH and rarely shock, renal failure, DIC and even death. Perinatal complications in the form of RDS, perinatal asphyxia, preterm birth, IUGR, neonatal death, IUD, hypoglycaemia and neonatal jaundice were common affected pregnancies merit close surveillance. Early diagnosis, proper maternal and fetal monitoring, and timely intervention can prevent adverse maternal and fetal outcome. Proper maternal care units, with intense antepartum and intrapartum fetal surveillance facilities need to be established. Neonatal intensive care units (NICUs) need to be equipped with all facilities to cater to the needs of neonates with preterm birth and perinatal asphyxia. A coordinated team approach that includes the primary care physician, obstetrician, hepatologist is often required to promote good maternal and fetal outcome.

Funding: No funding sources Conflict of interest: None declared

Ethical approval: The study was approved by the Institutional Ethics Committee

\section{REFERENCES}

1. Ching CL, Morgan M, Hainsworth I, Kingham JG. Prospective study of liver dysfunction in pregnancy in Southwest Wales. Gut. 2002;51(6):876-80.

2. Alokananda R, Tata RJ, Roshan B. Nature and outcome of pregnancy in Obstetric Cholestasis. Obstet Gynecol India. 2005;55. 
3. Padmaja M, Bhaskar P, Kumaret GJ. Study of Obstetric Cholestasis. J Obstet Gynecol India. 2010;60(3):225-31.

4. Mishra N, Mishra VN, Thakur P. Study of Abnormal Liver Function Test during Pregnancy in a Tertiary Care Hospital in Chhattisgarh. J Obstet Gynaecol India. 2016;66(1):129-35.

5. Riely CA. Hepatic disease in pregnancy. Am J Med. 1994;96(1):18-22.

6. Rasheed S, Afghan S, Mazhar SB. Fetomaternal outcome in Liver diseases. Int $\mathrm{J}$ Sci res. 2015:21(25):27.

7. Romero AJF, Lara GAL. Maternal morbidity and mortality in HELLP syndrome. J Obstet Gynecol. 2008;36(12):1175-90.

8. Dsouza AS, Gupta G. Maternal and fetal outcome in liver diseases. Int J Sci res. 2015:21(25);27.
9. Tiwari A, Srivastav R. Spectrum and outcome of liver diseases in pregnant women.int J Reprod Contracept Obstet Gynecol. 2017;6(8):3642-5.

10. Patra S, Kumar A,Puri M, Sarin SK. Maternal and fetal outcomes in pregnant women. Ann Intern Med. 2007;14(1):28-33.

11. Sumangali PK, Kurian S. Study of abnormal liver function tests in pregnancy in North Kerala 2017;5(12):5193-6.

Cite this article as: Farooq R, Beigh M, Abas R, Amin Y. Maternal and fetal outcome in liver disorders in pregnancy. Int $\mathrm{J}$ Basic Clin Pharmacol 2021;10:1121-4. 